\title{
Clinical Consequences of Untreated Dental Caries among Primary School Children: A Cross-Sectional Study
}

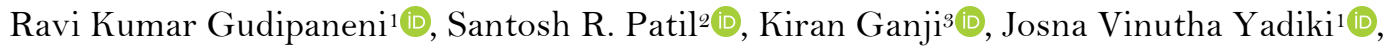 \\ Ali Assiry ${ }^{4}$, Mohammad Khursheed Alam ${ }^{5}(\mathbb{0}$
}

\begin{abstract}
'Department of Pediatric Dentistry, College of Dentistry, Jouf University, Sakaka, Saudi Arabia.
${ }^{2}$ Department of Oral Medicine and Radiology, College of Dentistry, Jouf University, Sakaka, Saudi Arabia.

${ }^{3}$ Department of Periodontology, College of Dentistry, Jouf University, Sakaka, Saudi Arabia.

${ }^{4}$ Department of Pediatric Dentistry, College of Dentistry, Najran University, Najran, Saudi Arabia.

${ }^{5}$ Department of Orthodontics, College of Dentistry, Jouf University, Sakaka, Saudi Arabia.
\end{abstract}

Author to whom correspondence should be addressed: Ravi Kumar Gudipaneni, Assistant Professor, Department of Pediatric Dentistry, College of Dentistry, Jouf University, Sakaka, Aljouf, Saudi Arabia. Post Box: 2014, Phone: +96 6540684272. E-mail: drravimds@gmail.com.

Academic Editors: Alessandro Leite Cavalcanti and Wilton Wilney Nascimento Padilha

Received: 02 April 2019 / Accepted: 13 November 2019 / Published: 04 December 2019

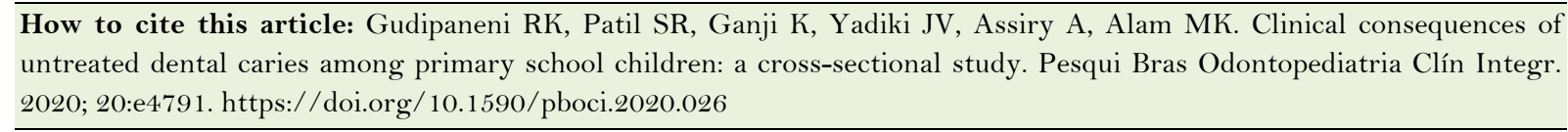

\begin{abstract}
Objective: To evaluate the dental caries experience and clinical consequences of untreated dental caries (UDC) among primary school children of Al Jouf region, Saudi Arabia and to determine the correlation between dental caries experience and clinical consequences of UDC. Material and Methods: A 250 primary school children 6-7 years were recruited using systematic random sampling. The prevalence of dental caries in deciduous dentition was assessed by following WHO criteria using the dmft index and the clinical consequence of UDC was assessed with the pufa index. The pufa score was calculated cumulatively following the pufa diagnostic criteria. The Student's t-test was used to equate the mean dmft and pufa scores between boys and girls. The correlation between the dmft and the pufa scores was evaluated using Pearson's correlation coefficient (r), and the p-value was set at 0.05 for statistical significance. Results: Out of which $154(61.60 \%)$ boys and $94(37.60 \%)$ were girls. The mean (SD) values of dmft for boys reported to be $5.37( \pm 3.31)$ and for girls 6.35 ( \pm 3.27$)$, which was statistically significant with gender $(\mathrm{p}<0.001)$. Statistically, significant mean values of pufa were $1.20( \pm 1.37)$ in boys and $1.71( \pm 1.58)$ in girls, respectively was observed $(\mathrm{p}<0.001)$. The Pearson correlation between $\mathrm{dmft}$ and pufa values showed a highly significant positive correlation among $\mathrm{dmft}$ and pufa values $(\mathrm{r}=0.635, \mathrm{p}<0.001)$. Conclusion: The present study revealed that high caries prevalence and experience of the clinical consequences of UDC in the primary dentition, and there was a strong positive correlation between $\mathrm{dmft}$ and pufa score values.
\end{abstract}

Keywords: Epidemiologic Methods; Dental Caries; DMF Index; Child. 


\section{Introduction}

Dental caries still remains a worldwide oral health problem, particularly in children [1]. Over the few decades, the dmft/DMFT index has been used widely to evaluate caries experience worldwide both in adults and children [2]. A drawback of this index is that it fails to record the untreated carious lesions (UDC) and its clinical consequences such as pulpal involvement, dental abscess, fistula, etc. Also, it does not reflect the treatment needs of a population at the individual and community level.

It is essential to identify and use an index that measures and estimate the clinical consequences of UDC among the population in epidemiological studies. A pufa/PUFA index has been developed to determine the severity of UDC, and various stages of clinical consequences resulted from UDC [3]. This index can be used with dmft/DMFT index to estimate the clinical consequences of UDC among the population [4].

There is a scarcity of studies regarding the clinical consequences of UDC among the primary school children of Al Jouf Province, Saudi Arabia. Hence, the present study was undertaken to measure the prevalence of dental caries, clinical consequences of UDC and to determine the correlation among dmft and pufa scores among the primary school children. In the present study, the null hypothesis tested was there is no relationship among dmft and pufa scores.

\section{Material and Methods}

\section{Study Design}

The present cross-sectional observational study was conducted among primary school children from the Al Jouf region, Saudi Arabia. A study population comprising 250 school children aged 6-7 years was selected using systematic random sampling. An initial study was carried out among 30 primary school children to find the feasibility of the present study. The study sample chosen in the initial study were not included in the main study sample. The children who have dental caries ( $>1$ lesion) and who gave voluntary consent from their parents/caregivers were included in the present study. Whereas, children with special needs and who refused to participate in the study were excluded. All the procedures were followed as per the guidelines of the declarations of Helsinki.

\section{Data Collection}

Participant's demographic data were collected through a questionnaire. The clinical examination was performed in the classroom of each school in a semi-supine position using artificial light and the dental caries was documented as defined by WHO by Community Periodontal Index (CPI) probe and dental mouth mirror [2]. The diagnosis of dental caries was done after drying the tooth surfaces by cotton rolls and using tongue blades. The clinical consequences of UDC were evaluated with the pufa index [3]. The criteria and codes for the pufa/PUFA index [3] are described in Table 1.

Table 1. Description of pufa/PUFA codes.

\begin{tabular}{cl}
\hline Code & Criteria \\
\hline $\mathrm{P} / \mathrm{p}$ & $\begin{array}{l}\text { Pulpal involvement is recorded when the opening of the pulp chamber is visible or when the coronal tooth } \\
\text { structure have been destroyed, the carious process and only roots or root fragments are left. No probing is } \\
\text { performed to diagnose pulpal involvement. }\end{array}$ \\
$\mathrm{U} / \mathrm{u}$ & $\begin{array}{l}\text { Ulceration due to trauma from sharp pieces of tooth is recorded when sharp edges of a dislocated tooth } \\
\text { with pulpal involvement or root fragments have caused traumatic ulceration of the surrounding soft tissues } \\
\text { e.g., tongue or buccal mucosa. } \\
\mathrm{F} / \mathrm{f}\end{array} \quad \begin{array}{l}\text { Fistula is scored when pus releasing sinus tract related to a tooth with pulpal involvement is present. } \\
\text { Abscess is scored when a pus containing swelling related to a tooth with pulpal involvement is present. }\end{array}$ \\
\hline
\end{tabular}


The pufa/PUFA score for the individual is counted cumulatively similar to the calculation of $\mathrm{dmft} / \mathrm{DMFT}$ score. Consequently, the score of pufa/PUFA score can range from 0 to 20 for the deciduous teeth and o to 32 for the permanent teeth [3]. The prevalence of pufa/PUFA is measured in the percentage of the population with a pufa/PUFA score of 1 or more, and the pufa/PUFA prevalence for a population is computed also as a mean value.

\section{Examiner Calibration}

Three investigators were trained and calibrated to use the pufa and dmft indices. Before the survey, the examiners underwent one-day clinical calibration, and the intra and inter-examiner reproducibility were measured using the Kappa $(\kappa)$ statistic. To ensure reliability during the study, each investigator re-examined $10 \%$ of the study population, and the reproducibility was evaluated; intra-examiner Kappa values for the three examiners (GR, JY and SP) were 0.82, 0.78 and 0.84, respectively, and inter-examiner Kappa value was 0.9 for dmft index. For the pufa index, intra examiner values were $0.81,0.74,0.79$, and inter examiners value was 0.8 .

\section{Statistical Analysis}

Statistical exploration of the data was accomplished by using SPSS 21.0. (IBM Corp, Armonk, NY, USA). Student's t-test was used to compare mean dmft and pufa scores between boys and girls. The correlation among the dmft and the pufa scores was measured by using Pearson's correlation coefficient (r) coefficient.

\section{Ethical Considerations}

The present study was performed by ethical guidelines and permitted by the Local Committee of Bioethics, Jouf University, Saudi Arabia (LCBE Approval No: 13-16-8/39).

\section{Results}

In total, 2506 - and 7-year-old children (154 [61.60\%] boys and 94 [37.60\%] girls) were involved in the present study. Dental caries experience and pufa values are reported in Table 1. The mean dmft scores for boys and girls were $5.37 \pm 3.31$ and $6.35 \pm 3.27$, respectively, which showed a significant statistically difference $(\mathrm{p}<0.01)$. Whereas the mean $\pm(\mathrm{SD})$ pufa scores were $1.2 \pm 1.37$ and $1.71 \pm 1.58$ for boys and girls, respectively, which also showed a statistically significant difference $(p<0.01)$ among both genders. It was observed that high mean value for the 'decayed' (d) component among the study population (4.62 $\pm 2.25,6.21$ \pm 3.26 boys and girls, respectively) with the higher mean value for girls. A high mean value for "pulpally involved' (p) teeth was observed than other components of the pufa index $(1.20 \pm 1.37,1.71 \pm 1.58$ boys and girls, respectively) (Table 2 ).

Table 2. The distribution of $\mathrm{dmft}$, pufa scores and their components.

\begin{tabular}{|c|c|c|c|c|c|c|}
\hline \multirow[b]{2}{*}{ Variables } & \multicolumn{2}{|c|}{ Frequency $(n>1)$} & \multicolumn{2}{|c|}{ Mean $\pm($ SD) } & \multirow[b]{2}{*}{ t-value } & \multirow[b]{2}{*}{ p-value } \\
\hline & $\begin{array}{l}\text { Boys } \\
\text { N (\%) }\end{array}$ & $\begin{array}{l}\text { Girls } \\
\mathrm{N}(\%)\end{array}$ & Boys & Girls & & \\
\hline Decayed (d) & $153(99.0)$ & $96(100.0)$ & $4.62 \pm 2.25$ & $6.21 \pm 3.26$ & -7.41 & $<0.01$ \\
\hline Missing (m) & $41(26.0)$ & $12(12.5)$ & $0.57 \pm 1.15$ & $0.22 \pm 0.62$ & 2.66 & 0.08 \\
\hline Filled (f) & $49(31.0)$ & $9(9.5)$ & $0.55 \pm 0.91$ & $0.17 \pm 0.56$ & 3.61 & $<0.01$ \\
\hline Overall dmft score $(>1)$ & $153(99.3)$ & 96 (100.0) & $5.37 \pm 3.31$ & $6.35 \pm 3.27$ & -5.22 & $<0.01$ \\
\hline Pulpally involved (p) & $79(51.0)$ & $62(65.0)$ & $0.72 \pm 0.90$ & $1.50 \pm 1.74$ & -4.60 & $<0.01$ \\
\hline Ulceration $(\mathrm{u})$ & $8(5.0)$ & $0(0.0)$ & $0.05 \pm 0.22$ & $0.00 \pm 0.00$ & 2.28 & 0.023 \\
\hline Fistula (f) & $3(6.0)$ & $26(27)$ & $0.02 \pm 0.19$ & $0.27 \pm 0.44$ & -5.94 & $<0.01$ \\
\hline Abscess (a) & $9(6.0)$ & $\mathrm{O}(0.0)$ & $0.05 \pm 0.23$ & $0.00 \pm 0.00$ & 2.43 & 0.016 \\
\hline Overall pufa score $(>1)$ & $96(62.0)$ & $79(91.0)$ & $1.20 \pm 1.37$ & $1.71 \pm 1.58$ & -5.62 & $<0.01$ \\
\hline
\end{tabular}


Table 3 represents the correlation among dmft, and pufa scores showed a strong positive correlation, which was statistically significant $(r=0.635, \mathrm{p}<0.001)$.

Table 3. Pearson correlation between $\mathrm{dmft}$ and pufa values.

\begin{tabular}{cccc}
\hline Index & Mean (SD) & p-value & Pearson Correlation (r) \\
\hline $\mathrm{dmft}$ & $5.47 \pm 2.89$ & $<0.001$ & $\mathrm{r}=0.635$ \\
pufa & $1.21 \pm 1.31$ & $<0.001$ & \\
\hline Correlation is significant at the level 0.001 level. & &
\end{tabular}

Correlation is significant at the level 0.001 level.

\section{Discussion}

Early childhood caries is one of the major oral disease affecting children in Saudi Arabia [5,6]. The clinical complications of UDC may affect the child's quality of life because of pain, discomfort, inadequate diet and sleep disturbance. Besides, UDC in primary teeth may lead to developmental defects of their permanent successors [7,8]. Therefore, in the present study, the clinical consequences of UDC among the study population were measured by the pufa index. Moreover, this index provides reliable qualitative and quantitative information about the burden of UDC in population studies [9,10].

In the present study, a high mean value of dmft for boys and girls (5.37 and 6.35, respectively) and a statistically significant difference was observed among boys and girls concerning dental caries experience. The national prevalence of dental caries of Saudi children estimated at $80 \%$ for deciduous teeth with a mean dmft of 5.0. Whereas, for permanent teeth, which was $70 \%$ with a mean DMFT value of 3.5. It was observed that the WHO 2000 goals are still unmet for Saudi children [11]. In the current study, a high prevalence of caries was observed in the female group. The reasons that females to experience higher caries are not clearly agreed and vary across populations, which could be due to early eruption of teeth in girls and consequently increased period of exposure to caries process, changes in dietary habits, utilization of preventive oral health programmes, hormonal or physiological changes, and characteristics of the dentition, enamel, saliva [12]. The high prevalence of dental caries in this study population is mainly associated with very poor oral hygiene practices, improper dietary behaviours, lack of dental awareness among children, inadequate use of dental services and late first dental visit among the study population [5].

The mean pufa index scores were $1.2( \pm 1.37)$ for boys and $1.71( \pm 1.58)$ for girls. It was evident that most of the UDC in the present study, suggestive of poor attitude of children and their parents towards oral health. These outcomes were similar to those obtained by other authors who reported that the mean prevalence of pufa/PUFA scores were $>0$ for 6- and 12-year-olds [3]. A study from the Riyadh region reported the mean pufa value was $0.67 \pm 1.74$, which was lower than Polish children, the mean dmft index values were 5.56 in 5year-aged children and 6.69 in 7-year-aged, and the pufa index was 2.20 and 2.44, respectively [13]. Even though dmft values in the present study were similar to those previously described [13], the pufa values were higher in their study. This could be due to the poor utilization of dental services. In the present study, the null hypothesis tested was rejected due to a strong correlation between dmft and pufa score. Thus, children with increased dmft scores would be at high risk for an increase in pufa scores. These outcomes are in accordance with the results of a former study in which the relationship between the prevalence of odontogenic infections and the UDC-pufa score were increasing and also dmft and pufa scores in deciduous teeth predict a higher dental caries risk in permanent teeth [14]. It was reported that the prevalence of clinical consequences of UDC was related with sociodemographic factors such as type of preschool, caregiver's age and the number of children in the family as well as psychological factors [15]. 
An oral health survey reports from the Philippines reported that among 6-year-aged children, the mean dmft was 8.4, and the mean pufa score was $3.4[16,17]$. These scores were higher than those in the present study; the high disease burden among Filipino children was attributed to the lack of effective caries control preventive measures and the limited access to primary oral health care. A study on suburban Nigerian school children reported that the mean dmft was 0.58 among children 4-6 years of age, and the mean pufa score was 0.16 [18]. These values were lower than the $\mathrm{dmft}$ and pufa values of the present study. Although a rise in consumption of Westernized foods by Nigerian children along with a lack of adequate facilities for oral health care, the prevalence of caries was low, the clinical consequences of UDC were still high. Furthermore, even though low mean dmft scores were reported in German [14] and Brazilian children [19], there was a strong positive correlation among dmft scores and pufa scores, as seen in the present study.

Some authors have suggested that the ' $f$ and ' $a$ ' code of the pufa index could be joined together since they are different stages of inflammation [19,20]. It was concluded that there is no need to score these codes separately [20]. The other criticisms of the pufa/PUFA index is the inclusion of the code 'u', which designates for traumatic ulceration and is usually not regarded as the complication of a UDC [21].

The use of the pufa/PUFA index as a supplementary to the traditional caries indices can estimate the neglected problem of the consequences of UDC. Moreover, the pufa index may be used for treatment planning and monitoring by epidemiologists and preventive oral health care providers. Therefore, the oral health care policy makers should consider the pufa score in planning and provision of health resources rather than the dmft score.

The limitations of the present study, it was a cross-sectional study design does not establish a causal relationship between the variables, and it does not include the other variables which act as confounding factors such as socioeconomic status, maternal education, oral hygiene practice, dietary habits, body mass index which may influence the dmft and pufa score. Further longitudinal studies will be needed in this Al Jouf region by considering the above variables.

\section{Conclusion}

The present study revealed high caries prevalence and its clinical consequences in the primary dentition. Also, there was a strong positive correlation among dmft and pufa scores. These observations indicate a need for oral health educational programs and dental care services to children in the Al Jouf region of Saudi Arabia.

\section{Authors' Contributions}

$\begin{array}{lll}\text { RKG } & \text { (D) 0000-0003-3616-4042 } & \begin{array}{l}\text { Conceptualization, Methodology, Investigation, Formal Analysis and Writing - } \\ \text { Original Draft Preparation. } \\ \text { Conceptualization, Methodology, Investigation, Formal Analysis and Writing - } \\ \text { Original Draft Preparation. }\end{array} \\ \text { KG } & \text { (D) 0000-0003-0715-497X-0002-3178-9513 } & \begin{array}{l}\text { Conceptualization, Methodology, Investigation, Formal Analysis and Writing - } \\ \text { Original Draft Preparation. }\end{array} \\ \text { JVY } & \text { (D) 0000-0002-8598-4605 } & \begin{array}{l}\text { Conceptualization, Methodology, Investigation, Formal Analysis and Writing - } \\ \text { Original Draft Preparation. }\end{array} \\ \text { AS } & \text { (D) } 0000-0002-3229-0503 & \text { Writing - Review and Editing. } \\ \text { MKA } & \text { (D) } 0000-0001-7131-1752 & \text { Writing - Review and Editing. }\end{array}$
$\begin{array}{ll}\text { All authors declare that they contributed to critical review of intellectual content and approval of the final version to be } \\ \text { published. }\end{array}$




\section{Financial Support}

None.

\section{Conflict of Interest}

The authors declare no conflicts of interest.

\section{References}

[1] Phantumvanit P, Makino Y, Ogawa H, Rugg-Gunn A, Moynihan P, Petersen PE, et al. WHO global consultation on public health intervention against early childhood caries. Community Dent Oral Epidemiol 2018; 46(3):280-7. https://doi.org/10.1111/cdoe.12362

[2] World Health Organization. Oral Health Surveys: Basic Methods. Geneva: World Health Organization; 2013.

[3] Monse B, Heinrich-Weltzien R, Benzian H, Holmgren C, van Palenstein Helderman W. PUFA - an index of clinical consequences of untreated dental caries. Community Dent Oral Epidemiol 2010; 38(1):77-82. https://doi.org/10.1111/j.1600-0528.2009.00514.x.

[4] Tiwari S, Dubey A, Singh B, Avinash A. Clinical consequences of untreated dental caries evaluated with the pulpal involvement-roots-sepsis index in the primary dentition of school children from the Raipur and Durg districts, Chhattisgarh state, India. Med Princ Pract 2015; 24(2):184-8. https://doi.org/10.1159/000369067

[5] Farooqi FA, Khabeer A, Moheet IA, Khan SQ, Farooq I, ArRejaie AS. Prevalence of dental caries in primary and permanent teeth and its relation with tooth brushing habits among schoolchildren in Eastern Saudi Arabia. Saudi Med J 2015; 36(6):737-42. https://doi.org/10.15537/smj.2015.6.10888

[6] Khan SQ, Khan NB, Arrejaie AS. Dental caries. A meta analysis on a Saudi population. Saudi Med J 2013;34(7):7444-9.

[7] Skeie MS, Raadal M, Strand GV, Espelid I. The relationship between caries in the primary dentition at 5 years of age and permanent dentition at 10 years of age - a longitudinal study. Int J Paediatr Dent 2006; 16(3):152-60. https://doi.org/10.1111/j.1365-263X.2006.00720.x

[8] Broadbent JM, Thomson WM, Williams SM. Does caries in primary teeth predict enamel defects in permanent teeth? a longitudinal study. J Dent Res 2005; 84(3):260-4. https://doi.org/10.1177/154405910508400310

[9] Vieira-Andrade RG, Martins-Junior PA, Correa-Faria P, Stella PE, Marinho SA, Marques LS, et al. Oral mucosal conditions in preschool children of low socioeconomic status: prevalence and determinant factors. Eur J Pediatr 2013; 172(5):675-81. https://doi.org/10.1007/s00431-013-1950-6

[10] Praveen BH, Prathibha B, Reddy PP, Monica M, Samba A, Rajesh R. Co Relation between PUFA Index and oral health related quality of life of a rural population in India: a cross-sectional study. J Clin Diagn Res 2015; 9(1):Zc3942. https://doi.org/10.7860/jcdr/2015/11427.5489

[11] Al Agili DE. A systematic review of population-based dental caries studies among children in Saudi Arabia. Saudi Dent J 2013; 25(1):3-11. https://doi.org/10.1016/j.sdentj.2012.10.002

[12] Shaffer JR, Leslie EJ, Feingold E, Govil M, McNeil DW, Crout RJ, et al. Caries experience differs between females and males across age groups in Northern Appalachia. Int J Dent 2015; 2015:938213. https://doi.org/10.1155/2015/938213

[13] Baginska J, Rodakowska E, Wilczynska-Borawska M, Jamiolkowski J. Index of clinical consequences of untreated dental caries (pufa) in primary dentition of children from north-east Poland. Adv Med Sci 2013; 58(2):442-7. https://doi.org/10.2478/v10039-012-0075-x

[14] Grund K, Goddon I, Schuler IM, Lehmann T, Heinrich-Weltzien R. Clinical consequences of untreated dental caries in German 5- and 8-year-olds. BMC Oral Health 2015; 15(1):140. https://doi.org/10.1186/s12903-015-0121-8

[15] Neves ÉTB, Perazzo MF, Gomes MC, Ribeiro ILA, Paiva SM, Granville-Garcia AF. Association between sense of coherence and untreated dental caries in preschoolers: a cross-sectional study. Int Dent J 2019; 69(2):141-9. https://doi.org/10.1111/idj.12439

[16] Monse B, Benzian H, Araojo J, Holmgren C, van Palenstein Helderman W, Naliponguit EC, et al. A silent public health crisis: untreated caries and dental infections among 6- and 12-year-old children in the Philippine National Oral Health Survey 2006. Asia Pac J Public Health 2015; 27(2):NP2316-25. https://doi.org/10.1177/1010539512469250.

[17] Benzian H, Monse B, Heinrich-Weltzien R, Hobdell M, Mulder J, van Palenstein Helderman W. Untreated severe dental decay: a neglected determinant of low Body Mass Index in 12-year-old Filipino children. BMC Public Health 2011; 11:558. https://doi.org/10.1186/1471-2458-11-558

[18] Oziegbe EO, Esan TA. Prevalence and clinical consequences of untreated dental caries using PUFA index in suburban Nigerian school children. Eur Arch Paediatr Dent 2013; 14(4):227-31.

https://doi.org/10.1007/s40368-013-0052-5

[19] Ferraz NK, Nogueira LC, Pinheiro ML, Marques LS, Ramos-Jorge ML, Ramos-Jorge J. Clinical consequences of untreated dental caries and toothache in preschool children. Pediatr Dent 2014; 36(5):389-92. 
[20] Holmgren C, van Palenstein Helderman W, Monse B, Heinrich-Weltzien R, Benzian H. Modifications to the PUFA index: are they justified at this stage? Med Princ Pract 2014; 23(3):292-3. https://doi.org/10.1159/000357271

[21] Frencken JE, de Souza AL, van der Sanden WJ, Bronkhorst EM, Leal SC. The Caries Assessment and Treatment (CAST) instrument. Community Dent Oral Epidemiol 2013; 41(1):e71-7. https://doi.org/10.1111/cdoe.12027 